\title{
Foreword by Richard Epstein
}

I first met Yun-chien Chang in the fall of 2005 when I visited New York University (NYU) for a week and gave a talk to Vicki Been's Land Use class, which Chang took as a LLM student. I think that it is fair to say that he knew me but I did not know him. Matters changed quickly in the fall of 2007, I taught contracts to one section of first year NYU students. Although a graduate student near completion of his doctoral degree in Juridical Science, he asked whether he could audit the course, and came faithfully throughout the entire semester. In 2008, he asked if he could audit my first year class in torts. Once again he faithfully attended every class. From those days forward we became close friends. Even though I did not supervise his doctoral dissertation, I did review it on several occasions in order to give my comments on the relationship between market valuations and condemnation values for various properties located in New York City.

From that initial project, Chang developed a deep interest in the problem of valuation in the context of eminent domain, which is reflected in the detailed and precise analysis that he offers on the wide range of issues that he covers in this slender volume. As he states at the outset, it is very easy for lawyers to underestimate the importance of valuation questions because they usually involve grubby questions of fact that resist easy generalization.

Nonetheless, first impressions on this subject can easily misinform, and in this instance they do. Speaking generally, valuation is not only an issue faced in dealing with eminent domain law. It also arises in a wide range of other contexts. Most close to eminent domain is of course the parallel question of valuation in connection with real estate taxation. As Chang notes, the incentives of the parties vary with these two contexts. The same landowners that opt strongly for a low valuation in a taxation system systematically claim that a higher valuation by far should be allowed when the property is subject to condemnation. For most real property owners, this year's real estate taxation is a constant worry, while the prospect of condemnation barely crosses their mind, so they try to skew the valuation to a lower value.

Once eminent domain is targeted, of course, the incentives shift radically, for now landowners want to elevate values that local governments 
(the typical condemner) wish to downplay. Getting the right value in the face of strong self-interest represents a challenge that most local practices fail to meet. But saying that systems don't work well should come as no surprise, for involuntary transactions always present more difficulties of execution than voluntary transactions, where the parties attach an agreedupon value to property that leaves both of them better off, and usually insures some level of cooperation between them.

Once this problem is identified, the question arises, what are the sources of the difficulty and what steps can be taken to counter them? The initial problem in all cases is to determine how the valuation should be set. If governments were always virtuous and knowledgeable, the proper valuation could well be zero. The state can compare the gains to the public to the losses of the owner, so as to initiate these transactions only when the social gains exceed the social losses. But knowledge is imperfect and government is subject to the powerful forces of self-interest, which calls for the adoption of some positive sum of compensation that government must pay once the property is taken. In dealing with this issue, Chang reviews the various standards and concludes that the proper measure, which is most invulnerable to political manipulation, calls for compensation at the fair market level of the property at its highest and best use, not just its current value.

Chang then further examines the various ways in which interested parties will try to game - that is, take unfair advantage of - this valuation system. In addition to the obvious efforts to tilt the evidence on valuation, he evaluates and dismisses the prospect that individual property owners will decide systematically to overinvest in property if they know that the fair market standard is in place. So long as value - and not cost-is the proper measure, he concludes that on balance the accurate market valuation is more resistant to manipulation than any lower standard, which gives a built-in incentive for governments to take these properties. That willingness to condemn at bargain rates is, moreover, often propelled by local developers who hope to purchase the property from the government for sums that are lower than their value. Recognizing the point is a useful corrective to those who assume that developers are always on the receiving end of government action, a result that surely happens in some but by no means all cases.

Given the multiple incentives that drive all parties when outsiders make valuations, the temptation arises to develop a variety of self-assessment schemes. These schemes seek to give property owners the incentive to set correct valuations on their property, often by giving others the option to purchase the property at the price that the owner sets for real estate taxation purposes. But as Chang points out, these systems are not likely 
to work for all sorts of reasons. The simplest one of these is that people do not learn about the value of their property until they are moved by extrinsic reasons to want to sell it. Quick: what is the present value of your house? Nor, it should be added, is it likely that these proposals can work in light of the genuine complexities that surround real estate transactions, including the heavy transfer taxes that are often imposed by state and local governments, the various inspections that are required by statute, the complexities of dealing with mortgages and liens at the time of forced sale, and the enormous inconvenience that persons evicted from their homes face in dealing with such mundane issues as housing relocation, job commutes, and schooling for their children. How these proposals would work in connection with condominiums and cooperatives where board approvals are necessary for transfers of possession is not clear either. It is no wonder that none of these programs has ever had the slightest political salience.

In the end, therefore, it seems as though we are stuck with the current methods of valuation, and on this score, data from both New York City and Taiwan lend solid support to two propositions that we all wish were false: valuations are inaccurate and political influence plays a role throughout the process. There is no magic bullet to deal with these recurrent difficulties of evaluation. Incremental improvements are the most that anyone can expect, and the least that anyone should accept. 